\title{
СЕМАНТИЧЕСКАЯ ДИФФУЗНОСТЬ ВРЕМЕННЫХ ДЕЙКТИЧЕСКИХ СЛОВ И ЕЕ ПРАГМАТИЧЕСКАЯ ФУНКЦИЯ
}

\section{SEMANTIC FUZZINESS \\ OF TEMPORAL DEICTIC WORDS AND ITS PRAGMATIC FUNCTION}

Qu Rui

Summary: The article is devoted to studying semantic fuzziness of temporal deictic words and its pragmatic function. The research aims to systematically reveal the features of semantic fuzziness of temporal deictic words. The study is original in emphasizing the importance of semantic fuzziness for speech communication. The research determines the types of semantic fuzziness of temporal deictic words and generalizes its pragmatic functions in speech communication.

Keywords: semantic fuzziness, temporal deictic words, types of fuzziness, pragmatic function, speech communication.

\section{Введение}

4 еловеческое восприятие объективного мира развивается от расплывчатого к ясному и точному. В данном процессе формируются такие абстрактные понятия, как время, пространство и т.д. Понятие передано посредством слова, а словесное значение составляет понятие. Под влиянием субъективного понимания человеком внешнего объективного мира понятия на разных уровнях обладают расплывчатостью. При употреблении слова для указания на некое понятие с расплывчатостью язык обретает семантическую диффузность, под которой подразумевается недоопределенность содержания языковых знаков [6, с. 43]. В то же время семантическая диффузность, как одна из естественных характеристик языка, оказывает существенное влияние на познание, мышление и общение человека, привлекая широкое внимание ученых со всего мира.

Не подлежит сомнению, что время в языке представляет собой типичное понятие, характеризующееся семантической диффузностью. Категория времени занимает важное место в мировоззрении человека и играет важную роль в формировании его отношения к миру. Российский исследователь Е. В. Тарасова подчеркивает, что «посредством понятия времени в сознании человека оформляется понимание направленности естественного и общественного процессов, отношение к настоящему, прошлому и будущему, определяется смысл человеческого бытия» [5, с. 42]. Как в области экстралингвистики, так и в области лингвистики ученые с разных сторон и на
Аспирант, Пекинский университет иностранных языков,

2. Пекин, КНP

qurui@yandex.ru

Аннотация: Статья посвящена исследованию семантической диффузности временных дейктических слов и ее прагматической функции. Целью исследования является системное раскрытие особенностей семантической диффузности временных дейктических слов. Научная новизна исследования заключается в том, что подчеркнута важность семантической диффузности для речевой коммуникации. В результате исследования были определены типы семантической диффузности временных дейктических слов, обобщены ее прагматические функции в речевой коммуникации.

Ключевые слова: семантическая диффузность, временные дейктические слова, типы диффузности, прагматическая функция, речевая коммуникация.

разных уровнях исследуют понятие времени и его выражение. Хотя ученые в разных областях определяют время по-разному, среди ученых существует единодушное мнение, что само время представляет собой континуум. В языке при образовании слов, указывающих на понятие времени, непрерывное временное течение искусственно разделяется на различные периоды и категории, в связи с этим многие временные слова неизбежно обретают семантическую диффузность.

Временные слова могут быть разделены на номинативные и дейктические. В качестве главного средства выражения темпорального дейксиса временные дейктические слова обладают ситуативностью, эгоцентризмом, субъективностью, мгновенностью и эфемерностью актуального значения [3, с. 5-6]. В дейктических словах чаще обнаруживается семантическая диффузность. Наше исследование стремится именно к раскрытию особенностей семантической диффузности временных дейктических слов.

Актуальность настоящего исследования заключается в том, что, во-первых, семантическая диффузность временных дейктических слов оказывает большое влияние на эффект речевой коммуникации и понимания текстов. Во-вторых, данная проблема недостаточно исследована и систематизирована. Именно отсюда возникла потребность в более системном исследовании.

Для достижения поставленной цели решаются следующие задачи: 
1. установить временные дейктические слова, обладающие семантической диффузностью;

2. разделить типы семантической диффузности, отражающейся временными дейктическими словами;

3. определить прагматические функции семантической диффузности, реализующиеся в языковом выражении и речевой коммуникации;

Методы исследования включают в себя описательный метод, семантический анализ, прагматический анализ и метод функционального анализа.

Теоретической базой являются работы Ли Цяньцзюя (黎干驹) [9] и У Тепина (伍铁平) [12].

Практическая значимость работы заключается в том, что полученные результаты будут способствовать улучшению речевой коммуникации и понимания текстов.

\section{1. Семантическая $и$ ффузность временных Аейктических слов и ее типы}

Семантика временных дейктических слов в основном связывается с категорией времени. Согласно мнению А. В. Бондарко, категория времени разделяется на темпоральность, аспектуальность, таксис, временную локализованность и временной порядок [1, с. 3-9]. Опираясь на семантический анализ данных единиц, можно отметить, что временными дейктическими словами могут выражаться такие семантики, как отрезок времени, точка времени, последовательность и частотность. Надо подчеркнуть, что временные дейктические слова, выражающие отрезок времени, точку времени и частотность, скорее всего обладают семантической диффузностью. Например, на рассвете, утром, днем, вечером, ночью, весной, летом, осенью, зимой, в прошлом, в будущем, давно, недавно, только что, часто, редко, иногда, всегда, обычно.

Стоит подчеркнуть, что семантическая диффузность принадлежит к семантической неопределенности. При определении диффузности необходимо отличать ее от таких языковых явлений, как неконкретность, двусмысленность и т.д.

Суть семантической диффузности чаще обнаруживается в том, что поле объекта, обозначаемого словом, нечетко. Например, граница между двумя периодами «утро» и «день» характеризуется расплывчатостью. Что касается неконкретности, она означает то, что в конкретном коммуникативном случае не дается подробная информация:

1. Он вчера приехал в отличном настроении (Кудлак Я. Симбиоз // «Наука и жизнь». 2009. НКРЯ) [4].

2. Я приехал в Петербург вчера в два часа (Киреевский И. В. Письма родным. 1830. НКРЯ) [Там же].
В первом предложении информация о времени дается неконкретно, а во втором - более конкретно. Между неконкретностью и диффузностью отсутствует неизбежная связь. Как в неконкретном, так и конкретном выражении может обнаруживаться семантическая диффузность. Например, по сравнению со словом «сегодня», выражение «сегодня утром» более конкретно, но «сегодня утром» указывает на диффузное время. Причина заключается в том, что грань между утром и днем трудно полностью расчистить.

Диффузность и двусмысленность также часто путают. Двусмысленность - это явление, в котором языковая единица или структура имеет две или больше интерпретаций [10, с. 26]. Двусмысленность обусловлена структурой слов или высказываний, их семантика и намерение говорящего не считаются диффузными [8, с. 9]. В связи с отсутствием конкретной конситуации появляется двусмысленность. В русском языке под влиянием особенностей словообразования временные дейктические слова сами не характеризуются двусмысленностью, здесь в качестве примера возьмем слово китайского языка. Китайское слово 半天 [бань тянь]'полдня' обозначает не только половину дня, но и значительный промежуток времени (русское слово «полдня» означает лишь половину дня). Слово 半天 [бань тянь] 'полдня' само по себе обладает двусмысленностью, но говорящий в конкретной конситуации имеет свое словесное намерение, при этом отменена двусмысленность данного слова. Например:

1. 有些工作人员工作半天休息半天。(人民日报. 人 民日报出版社, 1951.11.12. BCC语料库) [7] /

[ю се гун цзо жэнь юань гун цзо бань тянь сю си бань тянь]

'Некоторые персоналы работают полдня, отдыхают полдня (Газета «Жэньминь жибао». Изд-во газеты «Жэньминь жибао». 12.11.1951. Корпус китайского языка ВСС) (здесь и далее перевод автора статьи. - Ц. Ж.)'.

2. 这个京剧班现有小演员30多名，每周排戏两个半 天。(人民日报. 人民日报出版社，1988.06.16. BCC语 料库) [Там же] /

[чжэ гэ изин изюе бань сянь ю сяо янь юань сань щи до мин, мэй чжоу пай си лян гэ бань тянь]

' $В$ этом курсе Пекинской оперы насчитывается более 30 маленьких актеров, репетиция проводится по полдня два раза в неделю (Газета «Жэньминь жибао». Изд-во газеты «Жэньминь жибао». 16.06.1988. Корпус китайского языка ВСС)'.

3. 我们在路口等了半天，也没等到出租汽车。(人民日 报. 人民日报出版社, 1986.08.27. BCC语料库) [Там же] / [во мэнь цзай лу коу дэн лэ бань тянь, е мэй дэн дао чу цзу ци чэ]

'Мы долго ждали на перекрестке и не дождались такси (Газета «Жэньминь жибао». Изд-во газеты «Жэньминь жибао». 27.08.1986. Корпус китайского языка ВСC)'. 
4. 他们的发言，我听了半天，也没有听懂几句。(人 民日报. 人民日报出版社，1996.02.27. BCC语料库) [Там же] /

[та мэнь дэ фа янь, во тин лэ бань тянь, е мэй ю тин дун изи изюе]

'Я долго слушал их выступление, но почти ничего не понимал (Газета «Жэньминь жибао». Изд-во газеты «Жэньминь жибао». 27.02.1996. Корпус китайского языка ВСС)'.

В первых двух примерах 半天 [бань тянь]'полдня' указывает на половину дня, а в остальных - значительный промежуток времени. Таким образом, двусмысленность может быть отменена в конкретной конситуации. Что касается семантической диффузности, она сама не может устраниться, но при определенных условиях диапазон указания слова меняется от расплывчатого к ясному. Например:

Утром в 6 часов я отправился поблагодарить капитана гвардейцев (Японский Н. Дневники святого Николая Японского: в 5 т. 1905. НКРЯ) [4].

В примере семантическая диффузность самого слова «утром» не устраняется, но с помощью добавления словосочетания «в 6 часов» диапазон указания слова «утром» стал более ясным.

В связи с ограниченностью объема статьи мы не можем здесь проанализировать различия семантической диффузности и всех подобных ей языковых явлений. На основе вышеуказанных существенных характеристик семантической диффузности нетрудно отличить ее от других подобных явлений. Вообще говоря, семантическая диффузность временных дейктических слов может быть разделена на следующие типы:

1. Семантическая диффузность, определяемая временным количеством: Время - это категория и понятие с количественным значением. Под семантической диффузностью временных дейктических слов преимущественно понимается количественная диффузность. В зависимости от различных часовых поясов и принципов разделения суток трудно определить продолжительность временного периода, обозначаемого словами типа «утром» и «вечером». Кроме того, определение конкретной частоты, обозначаемой дейктическими словами «часто» и «редко», реализуется с большим трудом.

2. Семантическая диффузность, определяемая временной границей: Возьмем слово «зимой» в качестве примера анализа. Астрономическая зима в Северном полушарии Земли длится с 22 декабря до 21 марта, в Южном полушарии с 22 июня до 21 сентября. Население Земли живет на разных географических широтах, в зависимости от широты Земли природные условия изменяются, что приводит к семантической диффузности слов типа «зимой». В конкретной коммуникативной ситуации начало зимы и конец осени смешивается, граница между зимой и весной расплывчата.

3. Семантическая диффузность, определяемая степенью приближения/удаления относительно точки отсчета: Дейктические слова типа «только что» «скоро» «недавно» указывают на приближение или удаление во времени относительно некой точки отсчета, их временная ориентация чаще зависит от момента речи говорящего, чем определяется субъективность дейктических слов данного типа. При употреблении данных слов нам нельзя зафиксировать их степень приближения к моменту речи или удаления от момента речи говорящего.

Надо подчеркнуть, что установление временной границы оказывает влияние на временное количество, поэтому некоторые временные дейктические слова одновременно характеризуются семантической диффузностью первого и второго типов. Кроме вышеуказанного, существует и речевая диффузность, которая появляется в конкретной речевой ситуации. Например:

Мне вчера ночью сразу несколько писем пришло на электронку (Сальников А. Б. Отдел // «Волга». 2015. HКPЯ) [4].

Семантика слова «вчера» не характеризуется диффузностью, но в этом примере под влиянием добавления слова «ночью» она стала диффузной. Причина заключается в том, что мы не можем определить, соответствует ли использование временных слов в речи временной логике. Под влиянием речевых привычек правильная логика времени может быть нарушена, т.е. говорящий использует слово «вчера» в сочетании со словом «ночью», когда время, о котором говорится, превысило 24 часа ночи, относится к раннему утреннему диапазону следующего дня. При этом данная информация о времени считается диффузной.

\section{Прагматическая функция семантической Аиффузности}

Влияние временных дейктических слов с семантической диффузностью на речевое общение характеризуется двойственностью. С одной стороны, временные дейктические слова с семантической диффузностью играют негативную роль в процессе коммуникации, что происходит главным образом потому, что семантическая диффузность в определенной степени нарушает принцип кооперации. Согласно мнению Г.П. Грайса, «твой коммуникативный вклад на данном шаге диалога должен быть таким, какого требует совместно принятая цель (направление) этого диалога» [2, с. 222]. Принцип кооперации разделяется на такие категории, как категория количества, категория качества, категория 
отношения и категория способа. Категория количества требуется: «Твое высказывание должно содержать не меньше информации, чем требуется (для выполнения текущих целей диалога)» [Там же, с. 222]. К категории способа относится общий постулат: «Выражайся ясно», и конкретные постулаты: 1) «Избегай непонятных выражений»; 2) «Избегай неоднозначности»; 3) «Будь краток (избегай ненужного многословия)»; 4) «Будь организован» [Там же, с. 223]. Появление семантической диффузности противоречит категории количества и категории способа, что иногда проводит к поражению речевой коммуникации.

С другой стороны, используя временные дейктические слова с семантической диффузностью, говорящий нарушает принцип кооперации с целью соблюдения принципа вежливости, который рассматривается как принцип взаиморасположения говорящих в структуре речевого акта. По мнению Дж. Лича принцип вежливости включает в себя такие максимы, как максима такта, максима великодушия, максима одобрения, максима скромности, максима согласия, максима симпатии [11, с. 90-91]. В связи с соблюдением принципа вежливости создается среда позитивного взаимодействия, при этом временные дейктические слова с семантической диффузностью могут выполнять положительную прагматическую функцию в речевом акте.

Не подлежит сомнению, что существование семантической диффузности не всегда относится к нарушению принципа кооперации. В определенной степени семантическая диффузность соответствует принципу качества, к которому относится постулат: «Не говори того, для чего у тебя нет достаточных оснований» [2, с. 223]. В целом, семантическая диффузность способна придать речи гибкость и выразительность.

В речевой коммуникативной деятельности говорящий иногда для достижения определенной цели оставляет в своем выражении простор для повышения речевой гибкости, проявляющейся в основном в следующих двух аспектах :

1. При отсутствии достаточных доказательств или предсказаний с учетом категории качества принципа кооперации используется слова с семантической диффузностью для повышения гибкости языкового выражения.

- Он в Турове родился, а несколько лет назад его семья переехала в посёлок Большевик (Богомолов А. Прирожденный убийца. 17-летний подросток бил пенсионеров табуреткой до смерти // «Известия». 2003.02.17. НКРЯ) [4].

- Я думаю, что на днях ты получишь приглашение (Семенов Н. Н. Из переписки с П. Л. Капицей. 1934. НКРЯ) [Там же].

2. Использование слов с семантической диффузно- стью позволяет уклоняться от существа дела, избежать прямо отвечать на вопросы, на которые трудно или неудобно отвечать.

А ты когда захочешь? - Ну я тебе тогда скажу. - Ну ладно (Разговоры дома, Москва (1971-1977) // Русская разговорная речь: Тексты / Академия наук СССР, Институт русского языка / Отв. ред. Е. А. Земская, Л. А. Капанадзе. М.: Наука. 1978. НКРЯ) [Там же].

Кроме того, в таких официальных мероприятиях, как дипломатические случая, пресс-конференции и т.д., правильное использование слов с семантической диффузностью способствует повышению гибкости языкового выражения, что проявляется в тактичности и вежливости речи. Например:

По сообщению Strana.ru, в последнее время между Кравченко и его подчиненными возник серьезный конфликт. Сам он заявил журналистам в этой связи, что наказал двух подчиненных ему дипломатов "за ряд грубых нарушений" (Новое русское слово. 2002.12.03. НКРЯ) [Там же].

В данном примере выражение «в последнее время» обладает семантической диффузностью, его употребление в определенной степени придает речи тактичность, что повышает гибкость выражения.

Что касается функции повышения выразительности речи, это имеет в виду то, что посредством образного выражения речь обретает яркость и красочность. Надо подчеркнуть, что в конкретном контексте словами, не имеющими временное значение, создаются выражения с диффузным временем, что усиливает яркость и красочность языкового выражения. Например:

- Да, конечно, Мэтти, помню. Но тогда тебя звали Мэтти Арнольд, правда? - Ну, это было три, а может, четыре мужа тому назад (Хаусман Ф. Встреча с судьбой. 1997. НКРЯ) [Там же].

Слово «муж» не относится к временным словам, не имеет возможности указывать на временную информацию. При сочетании с предлогом и числительным данное слово в определенной степени выполняет функцию темпорального дейксиса. Выражение «четыре мужа тому назад» характеризуется семантической диффузностью, оно может быть рассмотрено как стилистическое средство выражения юмора, оно делает речь более выразительной.

\section{Зак^ючение}

В нашем исследовании была проанализирована семантическая диффузность временных дейктических слов, разделены ее типы и установлены прагматические функции семантической диффузности в речевом акте. В 
результате решения поставленных задач мы пришли к следующим выводам.

1. Временные дейктические слова, выражающие отрезок времени, точку времени и частотность, чаще обладают семантической диффузностью. Семантическая диффузность временных дейктических слов может быть разделена на три типа, которые соответственно зависит от временного количества, временной границы и степени приближения/удаления относительно точки отсчета. Кроме того, в практической речи существует особый тип семантической диффузности — речевая диффузность.

2. Семантическая диффузность существенно отличается от таких аналогичных семантических явле- ний, как неконкретность, двусмысленность и т.д. Семантическая диффузность сама не может устраниться, но при определенных условиях диапазон указания слова меняется от диффузного к ясному.

3. В речевой коммуникативной деятельности говорящий посредством временных дейктических слов с семантической диффузностью реализует соблюдение категории качества, что повышает гибкость языкового выражения, проявляющуюся в тактичности и вежливости речи.

4. Слова, не имеющие временное значение, при определенных условиях способны указывать на время с семантической диффузностью, что в определенной степени усиливает яркость и красочность языкового выражения.

\section{ЛИТЕРАТУРА}

1. Бондарко А.В. Вид и время русского глагола (значение и употребление). М.: Просвещение, 1971. 239 с.

2. Грайс Г.П. Логика и речевое общение // Новое в зарубежной лингвистике: Вып 16. Лингвистическая прагматика. Сборник: Пер. с разн. яз. / Сост. и вступ. ст. Н.Д. Арутюновой и Е.В. Падучевой. Общ. ред. Е. В. Падучевой. М.: Прогресс, 1985. С. 217-237.

3. Кацнельсон С.Д. Содержание слова, значение и обозначение. М.: Едиториал УРСС, 2011. 112 с.

4. Национальный корпус русского языка (НKРЯ) [Электронный ресурс]. URL: http://ruscorpora.ru/ (дата обращения: 31.03 .2021$)$.

5. Тарасова Е.В. Языковое поле как единица дидактической типологии: Учеб. пособие для студентов 4-5-х курсов фак. иностр. яз. (англ. отд-ние). Киев: УМКВ0, 1991. $108 \mathrm{c}$.

6. Шкапенко Т.М. Семантическая диффузность в двуязычном аспекте // Вестник Балтийского федерального университета им. И. Канта. 2012. Вып. 8. С. 42-47.

7. 北京语言大学： BCC语料库 (Пекинский университет языка и культуры: Корпус китайского языка BCC) [Электронный pecypc]. URL: http://bcc.blcu. edu.cn/ (дата обращения: 31.03.2021).

8. 何自然. 再论语用含糊. 外国语. 2000, 1: 7-13. (Хэ Цзыжань. Дальнейшее исследование прагматической неопределенности // Journal of Foreign Languages. 2000. № 1. (. 7-13.)

9. 黎干驹. 模糊语义学导论. 北京: 社会科学文献出版社. 2007, 387页. (Ли Цяньцзюй. Введение в диффузную семантику. Пекин: Академическая пресса социальных наук, 2007. 387 с.)

10. 刘佐艳. 关于语义模糊性的界定问题. 解放军外国语学院学报. 2003, 26(4): 23-27. (Лю Цзоянь. 06 определении семантической диффузности // Journal of PLA University of Foreign Languages. 2003. № 26(4). C. 23-27.)

11. 索振羽. 语用学教程. 北京: 北京大学出版社. 2000, 223页. (Со Чжэньюй. Учебное пособие по прагматике. Пекин: Изд-во Пекинского университета, 2000.223 c.)

12. 伍铁平. 模糊语言学. 上海: 上海外语教育出版社. 1999, 434页. (У Тепин. Диффузная лингвистика. Шанхай: Шанхайская пресса по обучению иностранным языкам, 1999. 434 с.) 